\title{
Uma Arquitetura Pedagógica na Elaboração de Histórias Coletivas
}

\author{
Rosane Aragón ${ }^{1}$, Simone Bicca Charczuk¹, Mariangela Lenz Ziede ${ }^{2}$ \\ ${ }^{1}$ Faculdade de Educação - Universidade Federal do Rio Grande do Sul (UFRGS) \\ Prédio 12201 - Av. Paulo Gama, s/n CEP 90046-900 - Porto Alegre - RS - Brasil \\ ${ }^{2}$ Programa de Pós-Graduação da Universidade Alto Vale do Rio do Peixe (UNIARP) - \\ Rua Victor Baptista Adami - no 800 CEP 89500-000 - Centro - Caçador - Santa \\ Catarina - Brasil \\ \{rosane.aragon, sibicca, mariangelaziede\}@gmail.com
}

\begin{abstract}
This study aims to analyze how a pedagogical architecture called Collective Stories fostered cooperative processes. We analyzed the responses of 69 students of a pedagogy of distance learning course to an online questionnaire about the experience in the use of architecture. The data analysis allows us to affirm that architecture has provided two main complementary movements: a movement that demanded leadership by the students and a support movement for reconstruction of their ideas and actions. In general, students showed high levels of satisfaction with the networking interaction process and the product of cooperative work.
\end{abstract}

\begin{abstract}
Resumo. Esse trabalho tem por objetivo analisar como uma arquitetura pedagógica denominada Histórias Coletivas fomentou processos cooperativos. Analisamos as respostas de 69 alunos de um curso de pedagogia a distância a um questionário online sobre a experiência no uso da arquitetura. A análise dos dados obtidos permite afirmar que a arquitetura propiciou dois principais movimentos complementares: um movimento que demandou protagonismo por parte dos alunos e um movimento de suporte às reconstruções de suas ideias e ações. De modo geral, os alunos apontaram altos níveis de satisfação com o processo de interação em rede e com o produto do trabalho cooperativo.
\end{abstract}

\section{Introdução}

Esse trabalho, caracterizado como estudo de caso (Yin, 2002), tem por objetivo analisar como a utilização de uma arquitetura pedagógica denominada Histórias Coletivas, proposta no âmbito de um curso de pedagogia a distância, fomenta o engajamento dos alunos em processos cooperativos. Para tanto, estudos dedicados à problematização da aprendizagem em rede na Educação a Distância (EAD), arquiteturas pedagógicas e o conceito de cooperação desenvolvido por Piaget $(1973,1998)$ serão considerados na análise desses processos. A relevância desse trabalho se justifica na medida em que os cursos a distância tradicionalmente são propostos de forma massificada, bem como priorizam atividades que enfocam o trabalho individual (Belloni, 2002; Okada e Santos, 2003), ao contrário da proposta analisada que enfoca a aprendizagem em rede com o suporte das tecnologias digitais. 
V Congresso Brasileiro de Informática na Educação (CBIE 2016)

Anais dos Workshops do V Congresso Brasileiro de Informática na Educação (CBIE 2016)

\section{A aprendizagem em rede e a cooperação na Educação a Distância}

A aprendizagem em rede é apresentada, na literatura da área, como proposta que se opõe ao modelo de Educação a Distância baseado em turmas compostas por muitos alunos com as quais são desenvolvidos trabalhos individualizados e que não privilegiam a troca entre saberes aluno-aluno e aluno-formadores (tutores e/ou professores) (Nevado, Carvalho, Menezes, 2007; Santos, 2011). Além disso, enfoca a aprendizagem como construção dos alunos, em detrimento da transmissão de conhecimentos muitas vezes organizada no formato de apostilas. As propostas de EAD construídas a partir da ideia de aprendizagem em rede utilizam as tecnologias digitais como potencializadoras do trabalho cooperativo.

Dentre as pesquisas que se dedicam a pensar experiências de aprendizagem em rede podemos mencionar o trabalho de Queiroz e Bastos (2015) que investigou experiências de discentes de jornalismo multimeios em uma universidade da Bahia, com o auxílio da rede social Edmodo. Algumas conclusões deste estudo foram o aumento de contato entre os participantes, interesse em participar das discussões do grupo bem como aumento da colaboração nas atividades realizadas. Vale destacar também a pesquisa apresentada por Junior e Pimentel (2013) que versa sobre a avaliação da colaboração online na rede social Facebook. Neste trabalho, os autores apresentam um protótipo de aplicativo que pode ser integrado ao Facebook e utilizado pelos professores como ferramenta de apoio ao processo avaliativo. Outros trabalhos também se dedicaram a pensar as redes sociais como suporte para a aprendizagem e em especial para a aprendizagem cooperativa (Silva, Oliveira e Mota, 2015; Cunha e Almeida, 2014; Santos, Cabral, Patrício, Santos e Corado, 2015; Souza e Schneider, 2014)

Quanto ao conceito de cooperação, nos apoiamos na produção teórica piagetiana. No livro Estudos Sociológicos, o autor concebe a cooperação como "operações efetuadas em comum ou em correspondência recíproca" (Piaget, 1973, p. 22). Ressalta ainda que para que haja cooperação é necessário que os indivíduos possam pensar em torno de uma realidade comum, renunciando interesses próprios (Piaget, 1998). Na obra do autor genebrino encontramos ainda a ideia de que a coordenação dos pontos de vista e a descentração são condições necessárias para que a cooperação seja efetivada.

Foram localizados na literatura alguns trabalhos que se dedicaram a pensar a cooperação sob a ótica piagetiana, articulada com a educação a distância. Dentre eles, destacamos o estudo de Ramos (1997) que avaliou o sistema hiperNet como promotor do aprendizado da cooperação e autonomia, sendo que uma das conclusões apresentadas pelo autor é que tais aprendizagens ocorrem de forma conjunta. Além desse estudo, também destacamos o trabalho de Reategui e Notare (2004) que se ocupa da apresentação do desenvolvimento de um ambiente de aprendizagem de algoritmos que promove a aprendizagem cooperativa.

\section{A proposta do Curso de Pedagogia a Distância e as Arquiteturas Pedagógicas}

O Curso de Pedagogia a Distância, no qual se insere a arquitetura a ser analisada a seguir, vincula-se à Universidade Federal do Rio Grande do Sul. Conta atualmente com 250 alunos, divididos em três polos de apoio presencial. No que se refere à proposta pedagógica, o Curso propõe uma metamorfose dos modelos tradicionais de educação para um modelo interacionista, viabilizando o abandono de docentes e alunos da ideia do domínio sobre seus campos de saberes e sobre os espaços delimitados de atuação. $\mathrm{O}$ 
V Congresso Brasileiro de Informática na Educação (CBIE 2016)

Anais dos Workshops do V Congresso Brasileiro de Informática na Educação (CBIE 2016)

trabalho em rede e em comunidades de aprendizagens proporciona um trabalho interdisciplinar e uma intercomunicabilidade dos saberes.

O currículo do curso está organizado em torno de eixos que agregam e articulam os conhecimentos específicos teóricos e práticos em cada semestre, visto que os alunos são professores em serviço há alguns anos. Os eixos são compostos por interdisciplinas (grandes áreas que congregam conhecimentos específicos) e Seminário Integrador.

As estratégias pedagógicas implementadas no curso apoiam-se na utilização de arquiteturas pedagógicas diversas. As arquiteturas pedagógicas, conforme Carvalho, Nevado e Menezes, (2005), são concebidas como estruturas de aprendizagem que são pensadas na confluência de diferentes componentes, destacando-se a abordagem pedagógica, a tecnológica, a Educação a Distância e a concepção de tempo e espaço. Aragón (2016), enfocando as arquiteturas na perspectiva da ecologia cognitiva, (Levy, 2010), concebe as arquiteturas como "microecossistemas cognitivos" que englobam ideias epistemológicas relacionais, pedagogias abertas, tecnologias digitais e novos referenciais de tempo e espaço como condições "estruturantes" para as aprendizagens individuais e construções coletivas.

Para Nevado, Menezes e Vieira Jr. (2011), as arquiteturas pressupõem pesquisa, atividades interativas, autorais e coautorais, envolvendo tecnologias e abordagens pedagógicas problematizadoras. Esses componentes atuam de forma a provocar, por um lado, desequilíbrios cognitivos e, por outro, suportes para as reconstruções. Dessa forma, as arquiteturas propõem aos estudantes, atitudes ativas e reflexivas que, para a sua concretização, necessitam de suportes flexíveis e adaptáveis a diferentes contextos, capazes de gerar uma ampliação dos espaços e tempos da aprendizagem.

Nessa ideia, a tecnologia digital é um componente desses "microecossistemas cognitivos" que altera significativamente os contextos e as formas de interação e aprendizagens. As arquiteturas propõem deslocamentos que visam dar às tecnologias sentidos que ultrapassem o seu uso periférico e dissociado das práticas pedagógicas, ressignificando os papéis e as formas de mediação, bem como oferecendo condições "estruturantes" para as construções coletivas.

\section{Aspectos metodológicos: sobre a arquitetura pedagógica "Histórias Coletivas"}

A proposta dessa arquitetura pedagógica foi lançada no âmbito da interdisciplina Seminário Integrador II, correspondente ao segundo semestre do curso (2015/2). Os alunos foram convidados a elaborarem cooperativamente, no espaço wiki do Moodle ou no google docs, uma história em pequenos grupos, formados a partir da livre escolha dos participantes. Esses ambientes contemplaram as características funcionais para dar suporte à arquitetura, já que propiciaram as interações entre os grupos de estudantes, facilitando a autoria coletiva. Além disso, os ambientes permitiram o acompanhamento do processo de construção das aprendizagens individuais e coletivas, bem como ampararam as ações de mediação dos professores e tutores.

Inicialmente, os grupos deveriam escolher o gênero literário para a produção (suspense, drama, comédia...), sendo que essa escolha e a escrita do parágrafo inicial ocorreram em um encontro presencial da interdisciplina. Após essa escrita inicial, a elaboração do texto seguiu-se à distância, sendo que a mesma ocorreu em "rodadas", nas quais cada componente do grupo era convidado a elaborar um parágrafo, articulado com o anterior. A rodada terminava quando todos os participantes dessem sua contribuição e recomeçava na mesma sequência, até totalizar ao menos três rodadas. 
V Congresso Brasileiro de Informática na Educação (CBIE 2016)

Anais dos Workshops do V Congresso Brasileiro de Informática na Educação (CBIE 2016)

A figura a seguir ilustra um espaço de trabalho de grupo no google docs.

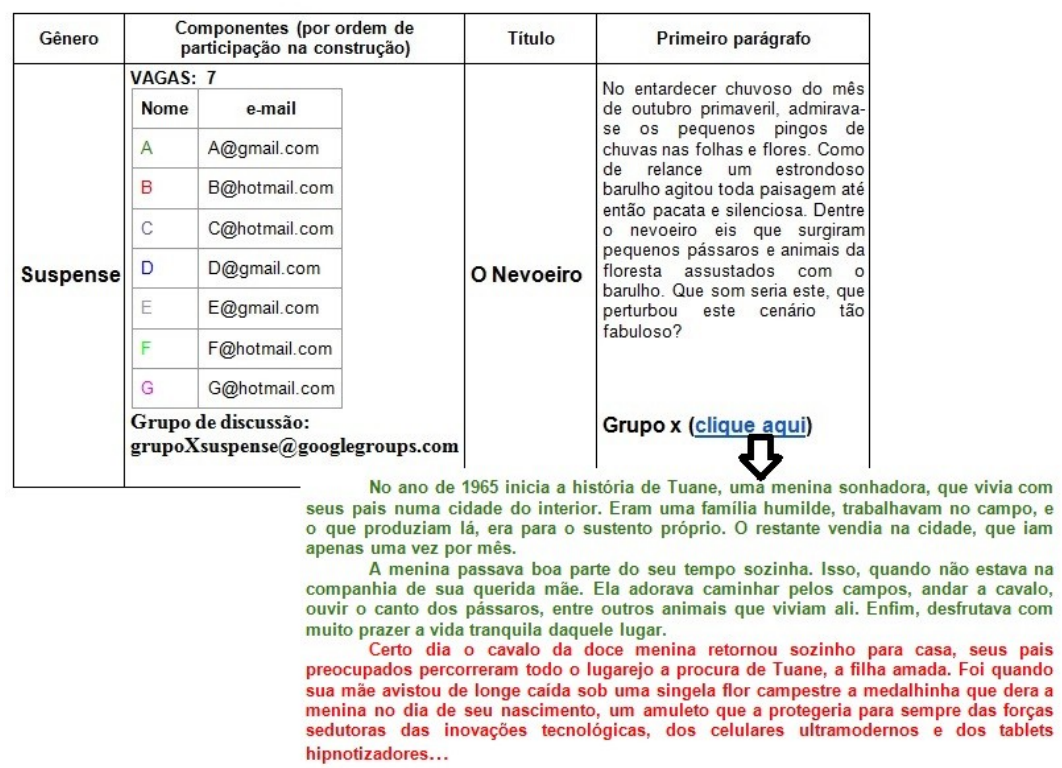

Figura 1. Espaço de trabalho de grupo no google docs

Após a realização da atividade, os alunos foram convidados a responderem um questionário online (LimeSurvey) sobre o desenvolvimento do trabalho, sua participação no mesmo, bem como a participação dos colegas de grupo. O questionário contou com questões relativas a distintas categorias, das quais destacamos para essa análise as seguintes: cooperação, dificuldades e superações e a história produzida. As perguntas admitiam respostas numa escala que variava entre "nada satisfeito" e "completamente satisfeito", havendo espaço para os respondentes escreverem comentários após cada grupo de questões.

\section{Análise da produção das Histórias Coletivas}

Foram selecionadas para análise as respostas das categorias (1) cooperação, (2) dificuldades e superações e (3) a história produzida. Para esse artigo, foram consideradas as respostas de 69 alunas, participantes de um dos polos do curso.

\subsection{Categoria Cooperação}

A categoria cooperação foi composta por quatro itens, a saber: "empenho pessoal na produção do texto", "empenho pessoal para cooperar", "respeito pessoal à regras do debate" e "respeito e valorização pessoal pela participação dos colegas". No que se refere ao "empenho pessoal na produção do texto", a maioria considerou satisfatória a sua participação $(49,28 \%)$, seguida pela opção muito satisfatória $(30,43 \%)$.

Com relação ao item "empenho pessoal para cooperar", 42,03\% dos alunos responderam que se sentiram satisfeitos com seu empenho e $27,54 \%$ muito satisfeito. Apenas dois alunos responderam que se sentiram pouco satisfeitos com seu empenho em cooperar. O comentário a seguir ilustra a dificuldade em cooperar, pois, embora tenham se mostrado satisfeitas com a realização da atividade, tal processo não ocorreu sem conflitos.

"Segui as determinações de postagens, gostei de "inventar" história, foi difícil deixar que outros seguissem ou mudassem o rumo da "minha" história”. (Suj.11). 
V Congresso Brasileiro de Informática na Educação (CBIE 2016)

Anais dos Workshops do V Congresso Brasileiro de Informática na Educação (CBIE 2016)

Podemos aproximar esse comentário com as teorizações piagetianas acerca da necessidade do desenvolvimento da descentração, pois para que a cooperação possa ser efetivada é necessário que o sujeito se desvincule do primado da perspectiva própria para incluir outros pontos de vista (Piaget, 1973, 1998).

Através dos registros em ambiente digital, os alunos realçam a importância da interação e do apoio mútuo para que o trabalho cooperativo pudesse acontecer. Por fim, os alunos ainda destacaram a importância do suporte tecnológico para a realização do trabalho e efetiva cooperação, demonstrando a importância da arquitetura pedagógica como estruturante das relações cooperativas:

"Cooperei da melhor forma que pude, as vezes nos comunicávamos por email, para nos ajudarmos”. (Suj.35)

"Diariamente entrava na página e verificava a nova postagem e copiava no meu computador. Criei um grupo no WhatsApp para lembrar as colegas da sua postagem”. (Suj. 20).

Quanto ao "respeito pessoal às regras do debate", a maioria dos respondentes consideraram-se satisfeitos $(37,68 \%)$ ou muito satisfeitos $(34,78 \%)$, sendo que três respondentes referiram que ficaram pouco satisfeitos com o respeito que tiveram em relação às regras do debate. A seguir, alguns comentários registrados ilustram o posicionamento dos alunos:

"Foi uma proposta muito interessante. Até hoje não havia feito nada parecido. Meu grupo foi muito coeso e cooperativo. A "rede" funcionou entre nós para a realização desta proposta”. (Suj. 57).

"Conseguimos nos manter equilibradas, ou seja, trabalhando cada uma com sua parte, mas cooperando com as colegas”. (Suj. 22).

Nesses excertos os alunos destacam novamente o processo cooperativo e sua ligação com a proposta do trabalho em rede. Destacamos, a partir desses comentários, a cooperação como "operar com" (Piaget, 1973) e a construção das aprendizagens em rede a partir da ação conjunta de todos os membros do grupo na elaboração do texto coletivo.

Finalizando a categoria cooperação, os alunos foram solicitados a mencionar sua satisfação em relação ao "respeito e valorização pessoal pela participação dos colegas". A maioria dos alunos se mostrou satisfeita $(42,03 \%)$ ou muito satisfeita $30,43 \%$ com a participação dos colegas. O item "pouco satisfeito" foi respondido por seis alunos.

"Acho que alguns colegas não leram a história na íntegra para poder dar a continuidade correta. O texto tornou-se repetitivo em alguns parágrafos”. (Suj. 7).

“Respeitei colegas, mas senti-me repreendido por colegas do grupo”. (Suj. 44).

Novamente visualizamos os conflitos que podem surgir no trabalho cooperativo e posicionamentos que podem dificultar a efetivação deste trabalho. Para que a cooperação seja exercida, é necessário o respeito mútuo, a valorização e a troca constante de ideias entre os parceiros de grupo. Tais elementos são exemplificados no comentário abaixo:

"Sempre que possível tento auxiliar as colegas do grupo, mas sempre respeito o direito que elas têm de não concordar ou gostar de algo”. (Suj. 8).

\subsection{Categoria Dificuldades e Superações}


V Congresso Brasileiro de Informática na Educação (CBIE 2016)

Anais dos Workshops do V Congresso Brasileiro de Informática na Educação (CBIE 2016)

A categoria "dificuldades e superações" é composta por quatro itens, a saber: "grau de dificuldades para expressar ideias ao iniciar a história", "superações em relação às dificuldades para expressar ideias", "dificuldades para seguir a ideia da (o) colega" e "superações em relação para seguir a ideia da (o) colega".

No que se refere ao "grau de dificuldades para expressar ideias ao iniciar a história", a maioria dos alunos avaliou ter experimentado dificuldades em um grau médio $(31,88 \%)$. Dos demais alunos, 30,43\% manifestaram a opção de grau de dificuldade baixo e $15,94 \%$ manifestaram terem encontrado um grau baixíssimo de dificuldade. Já $18,84 \%$ revelaram um alto grau de dificuldade e $2,90 \%$ um grau muito alto de dificuldade.

Ainda que a maior parte do grupo tenha optado por avaliar suas dificuldades em um grau médio e uma parte também significativa tenha expressado que teve poucas dificuldades, mais de $20 \%$ do grupo apontou alto grau de dificuldade para expressar as suas ideias em um trabalho de autoria coletiva. Alguns comentários podem ilustrar essas dificuldades:

“(...) Pois quando iniciei achei que não conseguiria, por ter dificuldades ao escrever”. (Suj. 66).

"Tive um pouco de dificuldade, pois não estou acostumada com tal proposta". (Suj. 38).

Com respeito às "superações", a maioria dos alunos (36,23\%) afirmou estar satisfeito com as superações realizadas quanto a expressão de ideias, 33,33\% deles manifestaram muita satisfação com as superações alcançadas e $23,19 \%$ se mostraram completamente satisfeitos com as superações. Apenas 7,25\% dos alunos se avaliam como pouco satisfeitos com as superações. Nenhum aluno manifestou estar nada satisfeito.

Considerando essa questão em conjunto com a anterior, destaca-se que a grande maioria dos alunos expressam altos níveis de satisfação em relação à superação de dificuldades, indicando que houve reconstrução das ideias a partir das interações. Apenas 5 dos 69 sujeitos participantes considera-se pouco satisfeito com as superações alcançadas. Como exemplo de comentários dos alunos destacamos:

"Exatamente porque tive que respeitar o pensamento alheio, sendo coerente com a história, mesmo tomando rumos que não me agradaram muito, que tive que cooperar pacientemente na continuação dela. Justamente aí que veio o desafio para mim. Após a conclusão continuo gostando de expressar minhas ideias, mesmo que para o outros também poderá não agradar”. (Suj. 29).

Em relação às "dificuldades para seguir a ideia da (o) colega", 33,33\% dos alunos considerou que as dificuldades ocorreram em um nível médio, enquanto 13,04\% encontraram níveis de dificuldade altos e muito altos. Já $31,88 \%$ consideraram que encontraram um nível baixo de dificuldade e $21,74 \%$ consideram que encontraram um nível muito baixo ou nenhuma dificuldade.

Ainda que um percentual significativo de alunos tenha manifestado facilidade para seguir a ideia do colega, 46,37\% dos alunos encontraram alguma dificuldade para seguir o texto desenvolvido pelo colega. As razões destacadas pelos alunos estão relacionadas a fatores, tais como: a manutenção da coerência/lógica da história, as mudanças de foco, ter que abrir mão das ideias em função do grupo e descentrar o pensamento. Com o extrato a seguir exemplificamos: 
V Congresso Brasileiro de Informática na Educação (CBIE 2016)

Anais dos Workshops do V Congresso Brasileiro de Informática na Educação (CBIE 2016)

"Dependendo do que era escrito, se faltavam argumentos que desencadeassem a história, ou elementos importantes que não foram mencionados na sequência da colega, ficava mais difícil de dar continuidade com lógica. Claro que cada uma de nós tem uma visão diferente do todo”. (Suj. 31).

Quanto à "superação das dificuldades", a maioria dos alunos se mostrou satisfeita $(43,48 \%)$, seguidos de $43,48 \%$ dos alunos muito satisfeitos com as superações e $24,64 \%$ completamente satisfeitos. Os alunos que se mostraram pouco satisfeitos com as superações somam $5,80 \%$. Nenhum aluno mostrou-se nada satisfeito.

Esses altos índices de satisfação indicam que os alunos puderam dar respostas aos desafios de compor coletivamente uma história a partir de uma arquitetura pedagógica que ofereceu um suporte estruturante para a autoria coletiva. Alguns comentários de alunos ilustram essas superações:

"A medida que a história foi sendo escrita, aprendemos a alinhar as ideias. Muito boa esta experiência”. (Suj. 16).

"Senti que foi uma atividade bem prazerosa, e com certeza vou colocar ela em prática nas próximas turmas que eu lecionar, é interessante pois temos que ler, reler e respeitar o que foi escrito pelo colega anterior, mesmo que discordamos da sua ideia e temos que dar seguimento com que pensamos”. (Suj. 45).

\subsection{Categoria História Produzida}

$\mathrm{Na}$ categoria "História produzida", no que se refere ao item "consistência nas argumentações", a maioria dos alunos 50,72\% afirmou estar satisfeita com as argumentações, 23,19\% manifestaram muito satisfação com a sua participação e dos colegas e apenas um aluno respondeu ter ficado nada satisfeito. Como exemplo de comentários de alunos que ficaram muito satisfeitos com a história destacamos:

"As argumentações foram boas, uma ideia sempre fechava com a outra. As argumentações tinham sentido, não foi criada uma história sem nexo”. (Suj. 53).

Conforme destaca Montangero e Maurice-Naville (1988, p. 121), "a cooperação, no sentido geral, consiste no ajustamento do pensamento próprio ao pensamento do outro, desta forma um controle mútuo é exercido entre as pessoas que cooperam". Podemos perceber pelo registro dos alunos que eles tinham ideias diferentes, mas conseguiam apreender a ideia dos colegas e dar uma sequência na história.

Outros alunos comentaram a necessidade de estarem atentos aos rumos que a história ia compondo e ajustando sua contribuição, se aproximando do que Montangero e Maurice-Naville (1988, p. 123) destacam como características do processo cooperativo: "o indivíduo atinge a construção de normas por um ajustamento das interações" e "os erros do pensamento entregues a si mesmo corrigem-se graças as trocas entre os membros". Piaget (1998, p. 80-81) destaca ainda que é necessário "[...] corrigir e superar o ponto de vista imediato, para situá-lo num sistema de conjunto capaz de coordenar essa perspectiva particular com um número crescente de visões diferentes". Tais elementos podem ser percebidos nos extratos abaixo:

"Percebia que algum escritor queria ir para um lado da história e vinha outro e seguia onde estava, e outro tentava ir para outro lado, mas ainda assim a história manteve um rumo, e no final 'aterrisou'”. (Suj. 48).

"Quando aconteciam os erros na história, a perda do objetivo inicial, os alunos retomavam o significado da história, que no caso do comentário do aluno, era uma história de terror". (Suj. 63). 
V Congresso Brasileiro de Informática na Educação (CBIE 2016)

Anais dos Workshops do V Congresso Brasileiro de Informática na Educação (CBIE 2016)

Outra questão respondida pelos alunos a respeito da história produzida foi sobre a "Inventividade das contribuições individuais". Nesta questão a maioria dos alunos $(55,07 \%)$ afirmou estar satisfeito com as contribuições individuais na história produzida e 20,29\% manifestaram muita satisfação com a participação das colegas. Apenas 11,5\% dos alunos se mostraram pouco satisfeitos com as argumentações alegando que:

"Alguns não colaboraram não participando na sua vez e ainda tinha outros que pareciam ter receio de acrescentar um fato novo na história”. (Suj. 2).

Já os que responderam que estão satisfeitos comentaram que:

“Consegui imaginar e inventar de acordo com a ideia do grupo”. (Suj. 59).

"Cada colega teve que usar sua criatividade para introduzir uma nova memória a história seguido o que já tinha sido escrito. O grupo conseguiu inventar novas situações de forma produtiva”. (Suj. 5).

Pelos comentários podemos perceber que os alunos encontraram espaços para criar. As regras foram seguidas pelo grupo sem coerção, mas pela vontade em dar uma continuidade a história e chegar num final que todos ficassem satisfeitos.

Na questão sobre o "encadeamento de ideias" a maioria dos alunos se mostrou satisfeito com o encadeamento $(40,58 \%)$ ou muito satisfeito $(27,54 \%)$ com a participação dos colegas no encadeamento da história. O item "pouco satisfeito" foi respondido por $18,84 \%$ dos alunos. O grupo avaliou ter conseguido dar um fio condutor a história, articulando o estilo e o pensar de cada um de forma harmônica.

"Estou satisfeito com o resultado e sei que cada um fez o seu melhor para a história ter um bom desfecho. Conseguimos dar seguimento das ideias apresentadas pelas colegas, pois o grupo seguiu o que foi pré-estabelecido nas conversas”. (Suj. 13).

"As ideias foram surgindo e sendo organizadas de acordo com o enredo escolhido pelo grupo”. (Suj. 42).

Podemos considerar que a cooperação foi construída no decorrer da arquitetura das histórias coletivas e no final os alunos, na sua maioria, ficaram satisfeitos com as vivências e com as produções. Segundo Montangero e Maurice-Naville (1998, p. 122), "a cooperação, fundada na igualdade, é uma forma ideal de relações entre indivíduos. Ela implica o respeito mútuo, o princípio de reciprocidade e a liberdade ou a autonomia de pessoas em interação".

\section{Considerações Finais}

Neste estudo buscamos analisar as potencialidades da arquitetura pedagógica "Histórias Coletivas" na promoção de processos cooperativos expressos em coautorias realizadas em rede. $\mathrm{O}$ uso dos ambientes digitais, como elementos integrantes dos microecossistemas cognitivos, viabilizaram as interações e as construções coletivas em diferentes tempos e convergindo em um mesmo espaço as contribuições de alunos que residem em diferentes localidades. No entanto, esses ambientes também apresentaram algumas limitações relacionadas à coordenação das atividades, tais como a identificação automática dos participantes, a notificação das modificações realizadas pelos participantes e algumas restrições de acesso. A experiência de uso permitiu observar os requisitos funcionais já explicitados e não funcionais (por exemplo, facilidade de uso) importantes para orientar a construção de uma ferramenta que contemple as especificidades da arquitetura. 
V Congresso Brasileiro de Informática na Educação (CBIE 2016)

Anais dos Workshops do V Congresso Brasileiro de Informática na Educação (CBIE 2016)

A análise dos dados obtidos na avaliação da experiência realizada pelos participantes nos permite afirmar que a arquitetura propiciou dois principais movimentos complementares: (i) um movimento desafiador para os estudantes, gerando conflitos iniciais por demandar o protagonismo dos alunos que fazem escolhas e definem caminhos de forma coletiva. Ou seja, os alunos são desafiados a assumirem uma maior proatividade no seu próprio processo de aprendizagem, ao mesmo tempo em que são colocados frente aos desafios inerentes aos processos de trocas em rede; (ii) um movimento de suporte às superações (no sentido das reconstruções), devido as suas características "estruturantes" e "organizadoras" que dão suporte e promovem as ações coletivas mediante o estabelecimento de acordos entre os participantes, incluindo-se os tempos e os espaços para o desenvolvimento das ações.

Esses movimentos foram constatados mediante o levantamento das respostas ao questionário e do acompanhamento das interações e produções. Os altos níveis de satisfação dos estudantes se mostram relacionados, para além da simples percepção de sucesso dos resultados na construção das histórias, aos próprios processos de trocas e ajustamentos recíprocos que levam a cooperação e, consequentemente, ao desenvolvimento do pensamento em diferentes contextos.

\section{Referências}

Aragón, R. (2016). Interação e mediação no contexto das arquiteturas pedagógicas para a aprendizagem em rede. Revista de Educação Pública. v. 25, n. 59/1, p. 261-275.

Belloni, M. L. (2002). Ensaio sobre a educação a distância no Brasil. Educação \& Sociedade, ano XXIII, $\mathrm{n}^{0} 78$.

Carvalho, M. J. S.; Nevado, R. A.; Menezes, C. S. (2005). Arquiteturas pedagógicas para educação à distância: concepções e suporte telemático. In: Simpósio Brasileiro de Informática na Educação, 16. Anais... [s/l]: [s/n], p. 362-372

Cunha, C. A. A., Almeida, L. C. (2014). Uso da Rede Social (Facebook) no Ensino e Aprendizagem da Língua Estrangeira (Inglês e Espanhol). Anais do $3^{\circ}$ Congresso Brasileiro de Informática na Educação (CBIE) - Workshops (WCBIE). p. 166.

Junior, N. N.; Pimentel, E. P. (2013). Avaliação da aprendizagem em mídias sociais: como avaliar a colaboração online? II Congresso Brasileiro de Informática na Educação (CBIE) - Workshops (WCBIE). p. 443-453.

Lévy, P. (2010). As tecnologias da inteligência: o futuro do pensamento na era da informática. 2. ed. São Paulo: Ed. 34.

Montangero, J.; Maurice-Naville, D. (1998). Piaget ou a Inteligência em Evolução. Porto Alegre: Artmed.

Nevado, R. A.; Carvalho, M. J. S; Menezes, C. S. (2007). Educação a distância mediada pela internet: uma abordagem interdisciplinar na formação de professores em serviço. In: Nevado, R. A.; Carvalho, M. J. S; Menezes, C. S. (orgs.). Aprendizagem em rede na educação a distância: estudos e recursos para formação de professores. Porto Alegre: Ricardo Lenz, p. 17-34.

Nevado, R.; Menezes, C.; Vieira Júnior, R. (2011). Debate de Teses - Uma Arquitetura Pedagógica. In: SBIE, 22.-WIE, 17, Aracaju. Anais do Evento. Aracaju: WIE, p. 820829.

Okada, A. L. P; Santos, E. O. (2003). Articulação de saberes na EAD: por uma rede interdisciplinar e interativa de conhecimentos. Anais do X Congresso Internacional de 
V Congresso Brasileiro de Informática na Educação (CBIE 2016)

Anais dos Workshops do V Congresso Brasileiro de Informática na Educação (CBIE 2016)

Educação a Distância, Porto Alegre, Brasil. Disponível em: http://people.kmi.open.ac.uk/ale/papers/a04abed2003.pdf.

Piaget, J. (1973). Estudos sociológicos. Rio de Janeiro: Forense.

Piaget, J. (1998). Sobre a Pedagogia: textos inéditos. São Paulo: Casa do Psicólogo.

Queiroz, M. P. C. P, Bastos, C. R. (2015). Utilização de redes sociais educativas em projeto de pesquisa na universidade. Anais do XXVI Simpósio Brasileiro de Informática na Educação, p. 1270-1273.

Ramos, E. M. F. (1997). Análise ergonômica do sistema hiperNet buscando o aprendizado da cooperação e da autonomia. Revista Brasileira de Informática na Educação, Número 1, s/p.

Reategui, E.; Notare, M. (2004). A3 - Ambiente de Aprendizagem de Algoritmos. Anais do XV Simpósio Brasileiro de Informática na Educação, p. 1-3.

Santos, G. F.; Cabral, M. K. F.; Patrício, P. C. S.; Santos, M. C.; Corado, V. A. (2015). Rede Social Google+: Análise de recursos para a aprendizagem colaborativa. Anais dos Workshops do IV Congresso Brasileiro de Informática na Educação - CBIELACLO. p. 635-643

Santos, G. L. (2011). Ensinar e aprender no meio virtual: rompendo paradigmas. Educação e Pesquisa, v. 37, n. 2, p. 307-320.

Silva, S. P.; Oliveira, C. E. T.; Motta, C. L. R. (2015). Promovendo a aprendizagem através das redes sociais apoiada por um modelo de combinação social. Revista Brasileira de Informática na Educação, v. 23, n. 01, p. 122-138.

Souza, A. A. N.; Schneider, H. N. (2014). O Facebook como espaço de interação, colaboração e aprendizagem: uma reflexão sob a perspectiva discente. Anais do $3^{\circ}$ Congresso Brasileiro de Informática na Educação - $20^{a}$ Workshop de Informática na Escola. p. 342-351.

Yin, R. K. (2002). Estudo de Caso. Porto Alegre: Bookman. 